\title{
Commentary: Greater Emotional Gain from Giving in Older Adults: Age-Related Positivity Bias in Charitable Giving
}

\author{
Mary B. Hargis ${ }^{1}$ and Daniel M. Oppenheimer ${ }^{2 *}$ \\ ${ }^{1}$ Department of Psychology, University of California, Los Angeles, Los Angeles CA, USA, ${ }^{2}$ Department of Psychology and \\ Anderson School of Management, University of California, Los Angeles, Los Angeles CA, USA
}

Keywords: charity, aging, older adults, gist based processing, donations

\section{A commentary on}

Greater Emotional Gain from Giving in Older Adults: Age-Related Positivity Bias in Charitable Giving

by Bjalkebring, P., Västfjäll, D., Dickert, S., and Slovic, P. (2016). Front. Psychol. 7:846. doi: 10.3389/fpsyg.2016.00846

Despite the fact that the population of is rapidly aging (Ortman et al., 2014), until recently scholars of charity have largely ignored older adults. Bjalkebring et al. (2016) begin addressing this gap

OPEN ACCESS

Edited by:

Emma V. Ward,

Middlesex University, UK

Reviewed by:

Elisa Di Rosa

University of Padua, Italy

*Correspondence:

Daniel M. Oppenheimer

daniel.oppenheimer@

anderson.ucla.edu

Specialty section:

This article was submitted to

Cognition,

a section of the journal

Frontiers in Psychology

Received: 23 June 2016 Accepted: 01 July 2016

Published: 14 July 2016

Citation:

Hargis MB and Oppenheimer DM

(2016) Commentary: Greater

Emotional Gain from Giving in Older

Adults: Age-Related Positivity Bias in

Charitable Giving.

Front. Psychol. 7:1075

doi: 10.3389/fpsyg.2016.01075 in the literature. By showing that increasing age is associated with stronger feelings of sympathy and compassion and that older adults are more likely to report feeling positive emotions when making donations, Bjalkebring et al. (2016) connect the literature on age-related positivity biases to the literature on philanthropy. We endorse this approach of identifying ways in which older populations differ from younger populations and exploring how those differences might inform donation behavior. Indeed, this tactic has the potential to reveal a large number of age-related differences in giving beyond those based on an age-related positivity bias.

It makes sense that Bjalkebring et al. (2016) focused primarily on emotional differences between older and younger adults, as the bulk of the literature on charitable giving has shown that people often give to charity for emotional reasons, and respond more strongly to emotional (than rational) appeals for donations (e.g., Loewenstein and Small, 2007; Huber et al., 2011). In fact, there are other emotional differences aside from positivity biases that have implications for donation behavior. For example, older adults often experience greater emotional complexity-that is, experiencing positive and negative emotions together (Carstensen et al., 2011). Therefore, it may be productive to interpret the higher levels of sympathy and compassion older adults reported in Bjalkebring et al. (2016) experiment 1 through the lens of older adults' improved ability to deal with emotional complexity above and beyond any bias toward purely positive emotions.

However, as important as emotion-related differences are to the study of aging and philanthropy, it is worth noting that there are also a number of cognitive factors that influence both older adults' processing of emotional information (such as manipulations of cognitive resources or goals; Reed et al., 2014; Reed and Carstensen, 2015), and giving more generally. Thus, exploring age-related cognitive differences has the potential to reveal additional insight as to how donation behavior changes across the lifespan.

Aging is related to cognitive declines in processing speed (Salthouse, 1996) and working memory capacity (Hasher and Zacks, 1989). Importantly, older adults are often able to compensate for these declines by directing cognitive resources toward information of high value (Castel, 2008). Younger adults sometimes find it difficult to discriminate between high-value information and 
low-value information (Castel, 2008), suggesting that they may not be as effective as older adults in identifying the worthiest causes or the most impactful ways in which to give. If older adults are sensitive to value when making spending decisions, they might be more likely than younger adults to donate, especially to causes they view as important. Older adults may also be better able to effectively determine the highest-value donation in terms of efficiency, personal value, or societal outcomes (for a discussion of younger adults' errors in optimizing the value of donations, see Baron and Szymanska, 2011).

Another strategy that older adults may use in light of cognitive declines is to engage in more gist-based processing, especially of monetary information (Castel, 2005). Rather than recalling exact details about studied items, older adults tend to remember general representations of those items, such as approximate value (e.g., remembering that an item costs "about $\$ 4.00$ " rather than "exactly \$3.92"), or relative value (e.g., which item cost less than another; Flores et al., 2016). Gist-based processing may have implications for how older adults decide when, how much, and to which causes they donate. If older adults make charitable giving decisions using gist, they may derive warm glow simply from the act of giving, irrespective of the exact dollar amount they donated. Younger adults' more accurate memory for exact prices may lead to different emotional responses to donations of different dollar amounts (for a discussion of the function mapping giving to utility in younger adults, see Strahilavitz, 2011). Furthermore, one of the most widespread "take home" messages that practitioners have derived from the scientific literature on philanthropy is that people are more likely to give (and give larger amounts) when presented with specific, tangible information about a charity's outcomes, as compared to more general information (e.g., giving a milking cow to a particular family, as opposed to general "poverty alleviation"; Cryder et al., 2013). If older adults process information using gist, their giving behavior may be less affected by tangibility than younger adults, as specific details may be lost in favor of a gist-based representation. In other words, common strategies for charitable appeals may be less effective on older populations.

\section{REFERENCES}

Baron, J., and Szymanska, E. (2011). "Heuristics and biases in charity," in The Science of Giving: Experimental Approaches to the Study of Charity, eds D. Oppenheimer and C. Olivola (New York, NY: Taylor and Francis), 215-235.

Bjalkebring, P., Västfjäll, D., Dickert, S., and Slovic, P. (2016). Greater emotional gain from giving in older adults: age-related positivity bias in charitable giving. Front. Psychol. 7:846. doi: 10.3389/fpsyg.2016.00846

Carstensen, L. L., Turan, B., Scheibe, S., Ram, N., Ersner-Hershfield, H., SamanezLarkin, G. R., et al. (2011). Emotional experience improves with age: evidence based on over 10 years of experience sampling. Psychol. Aging 26, 21-33. doi: $10.1037 / \mathrm{a} 0021285$

Castel, A. D. (2005). Memory for grocery prices in younger and older adults: the role of schematic support. Psychol. Aging 20, 718-721. doi: 10.1037/08827974.20.4.718

Castel, A. D. (2008). The adaptive and strategic use of memory by older adults: evaluative processing and value-directed remembering. Psychol. Earn. Motiv. 48, 225-270. doi: 10.1016/S0079-7421(07)48006-9
Scholars should also pay attention to a number of philanthropy-relevant demographic differences across age groups. For example, older adults' net worth is significantly higher on average than younger adults' (Taylor et al., 2011), and income is a major factor in charitable giving (Gittell and Tebaldi, 2006; Choi and Chou, 2010). Similarly, religious participation has been positively correlated with giving behavior (Jackson et al., 1995) and may be related to age (Davie and Vincent, 1998). These demographic differences are worth considering both because they themselves may be interesting avenues for exploring age-related differences in donation behavior, but also because they represent potential confounds in (inherently quasi-experimental) investigations on how aging affects giving. As noted by Bjalkebring et al. (2016), these sorts of confounds can make it difficult to distinguish between influences of aging, per se, and cohort effects.

In sum, findings by Bjalkebring et al. (2016) demonstrate how cognitive aging can influence charitable decision making and serve as motivation for many future avenues of exploration, including how emotional complexity, subjective value, and gistbased processing may affect charitable giving in younger and older adults. Established theories of cognitive aging can be a fruitful source of novel questions about how donation behavior changes across the lifespan, and may have applications for developing charitable appeals aimed at a rapidly increasing segment of the population.

\section{AUTHOR CONTRIBUTIONS}

The ideas and arguments were jointly developed by MH and DO. $\mathrm{MH}$ drafted the manuscript. Both authors edited the manuscript extensively.

\section{FUNDING}

The first author is partially supported by National Institutes of Health (National Institute on Aging), Award Number R01AG044335.
Choi, N. G., and Chou, R. J. A. (2010). Time and money volunteering among older adults: the relationship between past and current volunteering and correlates of change and stability. Ageing Soc. 30, 559-581. doi: 10.1017/S0144686X0999064X

Cryder, C. E., Loewenstein, G., and Scheines, R. (2013). The donor is in the details. Organ. Behav. Hum. Decis. Process. 120, 15-23. doi: 10.1016/j.obhdp.2012.08.002

Davie, G., and Vincent, J. (1998). Religion and old age. Ageing Soc. 18, 101-110. doi: $10.1017 / \mathrm{s} 0144686 \times 97006776$

Flores, C. C., Hargis, M. B., McGillivray, S., Friedman, M. C., and Castel, A. D. (2016). Gist-based memory for prices and "better buys" in younger and older adults. Memory doi: 10.1080/09658211.2016.1197944. [Epub ahead of print].

Gittell, R., and Tebaldi, E. (2006). Charitable giving: factors influencing giving in US states. Nonprofit Volunt. Sect. Q. 35, 721-736. doi: $10.1177 / 0899764006289768$

Hasher, L., and Zacks, R. T. (1989). Working memory, comprehension, and aging: a review and a new view. Psychol. Learn. Motiv. 22, 193-225. doi: $10.1016 /$ S0079-7421(08)60041-9 
Huber, M., Van Boven, L., and McGraw, P. (2011). "Donate differently: external and internal influences on emotion based donation decisions," in The Science of Giving: Experimental Approaches to the Study of Charity, eds D. Oppenheimer and C. Olivola (New York, NY: Taylor and Francis), 179-200.

Jackson, E. F., Bachmeier, M. D., Wood, J. R., and Craft, E. A. (1995). Volunteering and charitable giving: do religious and associational ties promote helping behavior? Nonprofit Volunt. Sect. Q. 24, 59-78. doi: $10.1177 / 089976409502400108$

Loewenstein, G., and Small, D. A. (2007). The Scarecrow and the Tin Man: the vicissitudes of human sympathy and caring. Rev. Gen. Psychol. 11, 112-126. doi: 10.1037/1089-2680.11.2.112

Ortman, J. M., Velkoff, V. A., and Hogan, H. (2014). An Aging Nation: the Older Population in the United States, Current Population Reports. Washington, DC:U. S. Census Bureau, 25-1140.

Reed, A. E., and Carstensen, L. L. (2015). "Age-related positivy effect and its implications for social and health gerontology," in Encyclopedia of Geropsychology, ed N. A. Pachana (Singapore: Springer Singapore), 1-9.

Reed, A. E., Chan, L., and Mikels, J. A. (2014). Meta-analysis of the age-related positivity effect: age differences in preferences for positive over negative information. Psychol. Aging 29, 1-15. doi: 10.1037/a0 035194
Salthouse, T. A. (1996). The processing-speed theory of adult age differences in cognition. Psychol. Rev. 103, 403-428. doi: 10.1037/0033-295X.103.3.403

Strahilavitz, M. (2011). "A model of the value of giving to others compared to the value of having more for oneself: implications for fundraisers seeking to maximize donor satisfaction," in The Science of Giving: Experimental Approaches to the Study of Charity, eds D. Oppenheimer and C. Olivola (New York, NY: Taylor and Francis), 15-34.

Taylor, P., Fry, R., Cohn, D., Livingston, G., Kochhar, R., Motel, S., et al. (2011). The Rising Age Gap in Economic Well-Being. Pew Research Center's Social and Demographic Trends, $1-38$.

Conflict of Interest Statement: The authors declare that the research was conducted in the absence of any commercial or financial relationships that could be construed as a potential conflict of interest.

Copyright $(2016$ Hargis and Oppenheimer. This is an open-access article distributed under the terms of the Creative Commons Attribution License (CC BY). The use, distribution or reproduction in other forums is permitted, provided the original author(s) or licensor are credited and that the original publication in this journal is cited, in accordance with accepted academic practice. No use, distribution or reproduction is permitted which does not comply with these terms. 